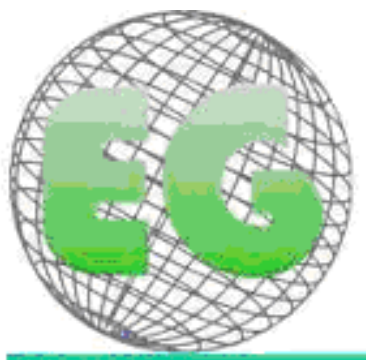

15SN 1696-6*5:

\title{
CLÍNICA
}

\section{HOSPITALIZACIÓN DE PACIENTES CON GRIPE A}

\section{HOSPITALIZATION OF PATIENTS WITH INFLUENZA A}

\author{
*Romero González, Juan Carlos. \\ *Diplomado en Enfermería. Hospital Universitario Virgen de Valme. Sevilla. \\ Palabras clave: Pandemia, virus influenza, prevención, aislamiento, OMS, contacto. \\ Keywords: Pandemic, Influenza Virus, Prevention, Isolation, WHO, Contact.
}

\section{RESUMEN}

Desde los primeros casos de muertes por Gripe A en Abril de 2009 se generó una "psicosis" social que se transmitió a todos los estamentos sociales y organizacionales reflejándose en los centros hospitalarios del sistema sanitario mediante aislamiento de contacto y gotas en pacientes con riesgo durante su hospitalización para evitar su propagación .Por todo ello, decidimos recoger los datos relacionados con este tipo de aislamientos y realizar un seguimiento de esta población y así hacer una comparativa entre los pacientes que resultaron Gripe A+ y Gripe A- , la evolución posterior de la enfermedad, hasta el momento, ha dado la razón a los datos obtenidos de nuestro estudio donde no hay datos significativos de mayores complicaciones, aunque sí en su intensidad de las mismas entre los miembros de la población de positivos con respecto a pacientes Gripe A negativos.

\section{ABSTRACT}

After the first cases of deaths due to Influenza A in April 2009 a social psychosis in every social class and organizational body was generated. This was reflected in hospital centers of the health system through patient isolation and drops in at risk patients during the hospital stay to avoid propagation. That is why, a collection of data related to these isolations was carried out, as well as a tracking of this population, in order to make a comparison between patients with Influenza A+ and Influenza A-. The subsequent evolution of the disease, so far, has agreed with the collected data of our study, with no important data of major complications. However, there are differences in intensity among the members of the population with Influenza A+ with regard to patients with Influenza A-. 


\section{INTRODUCCIÓN}

La OMS, el 11 de junio de 2009 elevó el nivel de pandemia de Gripe A a la fase 6 , que es considerarla pandemia moderada; la gravedad de la pandemia puede cambiar con el tiempo y eso se debe al cambio del virus, la vulnerabilidad subyacente y las limitaciones de los sistemas de salud(1).

Fue en México en Abril 2009 donde se detectaron los primeros casos y debido al elevado índice de contagio, al número de defunciones y a que la población de éstas tenía un elevado porcentaje en jóvenes sanos y al peligro de desborde en los servicios sanitarios se fue incrementando la alarma social(2) .

En España hasta enero de 2010 se han producido 271 muertes relacionadas con el virus H1N1 (3); a nivel mundial la Organización Mundial de la Salud OMS contabilizó en Abril de 2010 más de 17000 muertes en relación a dicho virus(4). Actualmente el virus se encuentra en un estado latente(5) como reflejan algunos expertos en la materia e indican que si se comporta como otras pandemias anteriores, la "segunda oleada" causará efectos "más patógenos o virulentos" que la primera.

El virus influenza H1N1 es uno de los descendientes de la gripe española que causó una pandemia devastadora en la humanidad durante el periodo 1918-1919.Tras la finalización de la pandemia el virus persistió en cerdos, y con ello, los descendientes del virus de 1918 han circulado en seres humanos durante todo el transcurso del siglo XX, contribuyendo a la aparición normal de gripe estacional anualmente (6,7). El brote de gripe H1N1 de 2009 fue causado por un reordenamiento de varias cepas de virus $\underline{\mathrm{H} 1 \mathrm{~N} 1}$, incluidas una humana, una aviaria y dos porcinas.(8)

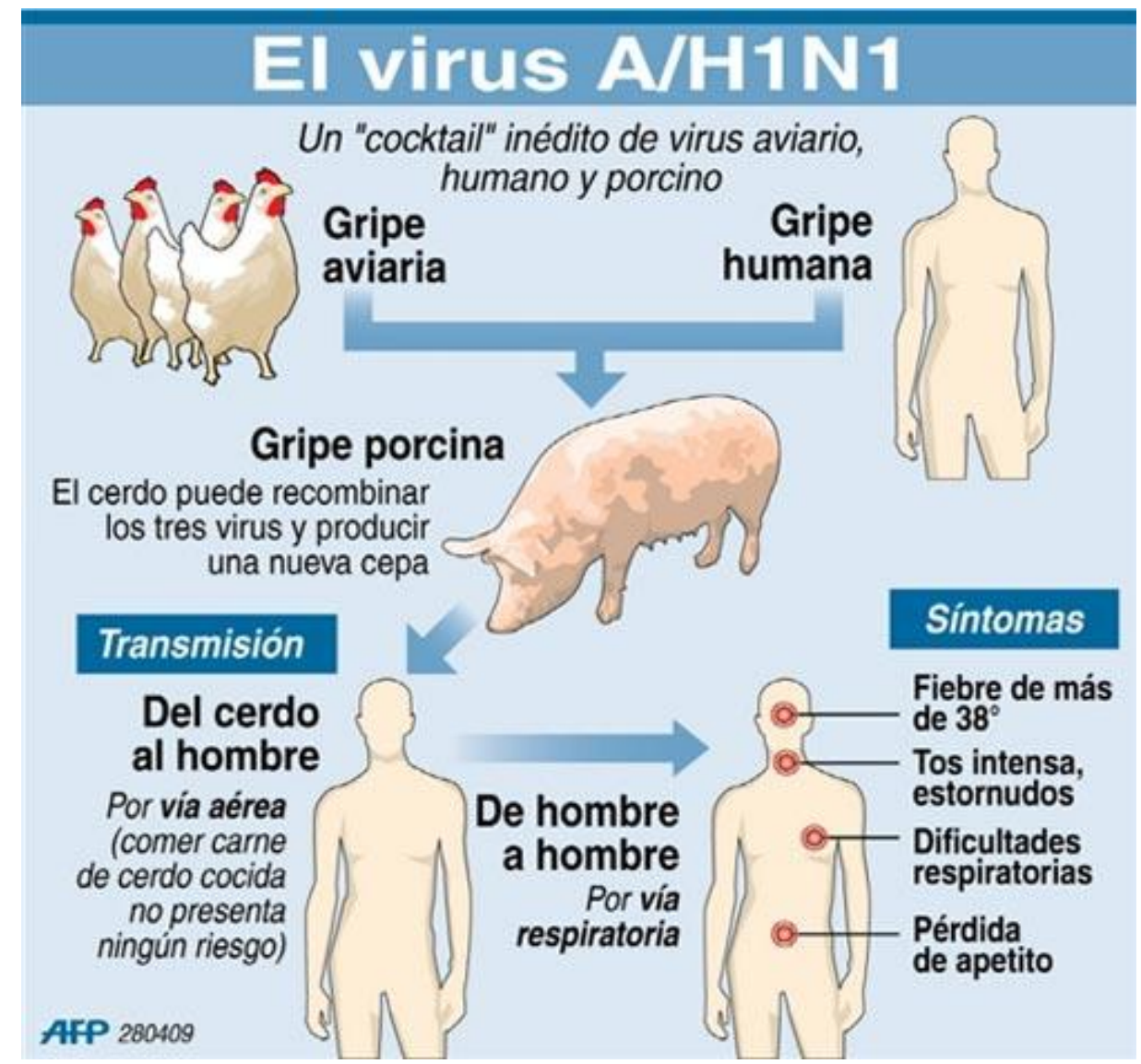


La gripe es una enfermedad que afecta desde la antigüedad a las personas y a otras especies animales (aves, cerdos...) y que causa epidemias cada año, principalmente durante los meses de invierno. Esta enfermedad la producen distintos tipos de virus que además pueden combinarse entre ellos dando lugar a una nueva gripe.

La gripe es muy contagiosa ya que se transmite fácilmente de una persona a otra a través de las gotitas de saliva o secreciones que expulsamos al hablar, toser o estornudar. La incidencia de la gripe $A$, a pesar de tener los mismos vehículos de transmisión, se ha comportado de forma diferente a la gripe estacional. Figura 1

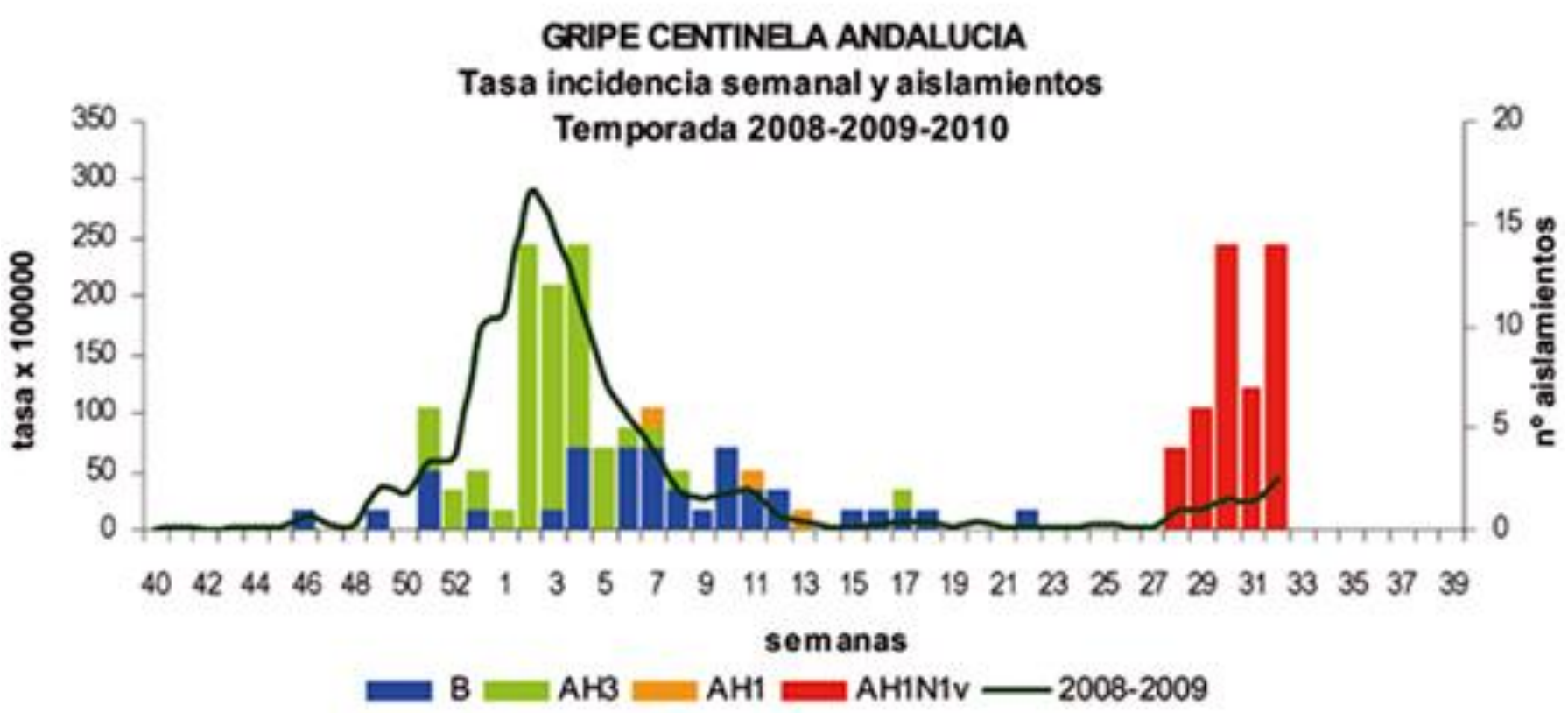

Los síntomas en seres humanos incluyen: aumento de secreción nasal, tos, dolor de garganta, fiebre alta, malestar general, pérdida del apetito, dolor en las articulaciones, vómitos, diarrea y, en casos de mala evolución, desorientación, pérdida de la conciencia y, ocasionalmente, la muerte(9) .La mayoría de los pacientes afectados forman parte de grupos en riesgo como personas extremadamente jóvenes o ancianas, enfermos crónicos y mujeres embarazadas, siendo un gran porcentaje de las muertes producto de complicaciones derivadas como neumonías.

Las personas que tienen un riesgo elevado de sufrir complicaciones debido a la infección por el nuevo virus de la influenza (H1N1) tienen las mismas características que las afectadas por la influenza o gripe estacional.(10) A medida que se disponga de más datos clínicos y epidemiológicos, se podrían revisar estos grupos de riesgo.

1. Niños menores de 5 años de edad. El riesgo de sufrir complicaciones graves debido a la influenza estacional es más alto en los niños menores de 2 años de edad.

2. Adultos de 65 años de edad o más.

3. Personas con las siguientes afecciones: 
- Enfermedad pulmonar crónica (incluida el asma), enfermedades cardiovasculares (excepto la hipertensión), trastornos renales, hepáticos, hematológicos (incluida la anemia de células falciformes 0 anemia drepanocítica), neurológicos, neuromusculares o metabólicos (incluida la diabetes mellitus);

- Inmunodepresión, incluidas las afecciones causadas por medicamentos o por el $\mathrm{VIH}$;

- Mujeres embarazadas;

- Residentes de instituciones para ancianos y otros centros de cuidados de enfermedades crónicas.

Las medidas y estrategias sanitarias han sido encaminadas a la prevención para evitar la propagación de la enfermedad y al tratamiento con oseltamivir en los casos de mayor morbilidad (11)

El Ministerio de Sanidad y Política Social y las Consejerías de Salud de las Comunidades Autónomas elaboraron un Plan de preparación y respuesta frente a la pandemia de gripe A. Los Comités y Subcomités de Expertos trabajaron en la elaboración y actualización de protocolos específicos, en el seguimiento de la pandemia y en la propuesta e implementación de medidas, tanto clínicas como sociales, que ayuden a gestionar la pandemia. Dentro de estas medidas sanitarias se establecieron a nivel del Servicio Andaluz de Salud el Aislamiento de contacto y gotas (Tabla 1), de todo paciente que presente síntomas compatibles de contagio de Gripe A y que requieran hospitalización en habitaciones individuales salvo en casos de confirmación de contagio positivo que pueden compartir habitación, todo ello bajo el seguimiento y asesoramiento de las Unidades de Medicina Preventiva de cada centro.( 12,13$)$ 


\section{Aislamiento de contacto}

Es el más frecuente y más importante modo de transmisión. Se divide en directo en indirecto.

La primera de ellas involucra el contacto de una superficie corporal con otra, permitiendo la transferencia física de microorganismos entre un huésped susceptible y una persona colonizada o infectada. Pueden ser transmitidos por esta vía estafilococos, estreptococos y entero bacterias. En tanto, el lavado de manos y el uso de barreras de protección como guantes y mandiles son suficientes para evitar la transmisión. La transmisión de contacto indirecto involucra el contacto de un huésped susceptible con un objeto contaminado, habitualmente inanimado, tales como instrumental, agujas, gasas y guantes usados. La vida del microorganismo en el ambiente es variable pudiéndose prolongar por largos periodo de tiempo, dependiendo del agente, las características del material y las condiciones del medio. No obstante, el papel de transmisión de este mecanismo no es de importancia, y la aplicación de medidas de prevención son muy complejas, por tanto generan mayor costo y ocasionan menor adherencia .

\section{Precauciones y medidas}

$\checkmark$ Colocar al paciente en una habitación común. Se dispondrá la ubicación del paciente en una habitación individual o el aislamiento por cohorte en casos de heridas extensas y en quemados.

$\square$ Guantes y mandil: Los que acceden a la habitación extremaran el uso de métodos de barrera como guantes y mandiles no siendo requisito que sean

estériles pudiendo solo estar limpios. El retiro de ambos materiales se realizara previo al abandono de la habitación.

$\square$ Equipos no críticos: Los equipos como estetoscopios, tensiometros, termómetro, chatas y demás serán de uso individual y adecuadamente procesados ( desinfectados o esterilizados) después del alta del paciente. Por la posibilidad de sufrir contaminación el manguito del tensiometro no debe estar en contacto con la piel del paciente pudiendo ocasionalmente usarse una tela fina para protegerlo como por ejemplo una mascarilla quirúrgica.

$\square$ Transporte de pacientes: Limitar el movimiento y transporte de los pacientes desde su habitación. El personal de salud deberá seguir las precauciones durante todo el trayecto, usando guantes para la movilización del paciente.

$\square$ Restricción de Visitas: Las visitas deberán ser restringidas, y orientadas.
Aislamiento de gotas

Ocurre a través del contacto próximo con un paciente. Las gotas tienen un diámetro mayor de $5 \mu \mathrm{m}$ y son generadas desde una persona fuente durante los episodios de tos, el estornudo, el habla, y en determinados procedimientos como aspiración y broncoscopia. La transmisión ocurre cuando las gotas generadas por una persona infectada y que contienen microorganismos son propagadas a una corta distancia y se depositan en las conjuntivas, mucosa nasal, o boca de un huésped susceptible. Las gotas recorren una distancia promedio de hasta un metro a parti del paciente fuente y rápidamente se depositan en el ambiente. Por tanto, la trasmisión no ocurre a distancias mayores, ni en periodos prolongados y no quedan suspendidas en el aire por ello no es necesario un manejo especial del aire para prevenir la transmisión. Como ejemplo podemos citar la meningitis meningococica, tos ferina, difteria, paperas, etc.

\section{Precauciones y medidas}

$\square$ Las precauciones estándar deben continuar siendo aplicadas

$\checkmark$ Ubicación del paciente: Se puede ubicar al paciente en una habitación individual o aplicar el aislamiento por cohorte. No se requiere manejo especial del aire y la ventilación. En áreas cerradas (Terapia Intensiva, Unidad Coronaria, Neonatología) separar a los pacientes por lo menos a 1 metro.

Mascarilla: Los que acceden a la habitación harán uso de mascarilla común. 
Todo paciente con sospecha de neumonía por influenza A (H1N1) debe ser ingresado en el hospital en caso de pertenecer a algún grupo de riesgo o existir cualquiera de los criterios detallados a continuación (14) :

- Embarazo.

- Enfermedad cardiovascular previa (excepto hipertensión arterial sistémica).

- Enfermedad pulmonar crónica (Incluye EPOC, fibrosis quística y asma moderadagrave).

- Diabetes mellitus y Obesidad mórbida (IMC>40).

- Insuficiencia Renal Crónica.

- Anemias y Hemoglobinopatías y otras enfermedades hematológicas.

- Hepatopatía crónica avanzada.

- Menores de 18 años en tratamiento prolongado con ácido acetilsalicílico.

- Inmunodeficiencias, incluida la causada por la infección por el VIH (linfocitos CD $+<200 / \mu l)$ o por fármacos o en los receptores de trasplantes

- Enfermedades neuromusculares graves y Asplenia

- Residencia en centros socio-sanitarios o geriátricos.

- Saturación de oxigeno por pulsioximetria $<95 \%$ respirando aire ambiente (si el paciente es portador de enfermedad cardiopulmonar crónica, considerar valores menores de saturación de oxígeno).

- $\mathrm{PaO} 2<70 \mathrm{mmHg}$.

- Shock o hipotensión (TAS $<90 \mathrm{mmHg}$ o TAD $<60 \mathrm{mmHg}$ ).

- Alteración del nivel de consciencia (confusión, agitación o convulsiones).

- Derrame pleural.

- Incapacidad para la ingesta oral.

- Problemática social que impida un adecuado manejo ambulatorio.

Dada la alarma socio-sanitaria creada ante esta pandemia decidimos marcar como objetivo la realización de un estudio que comparase las poblaciones que hubieran quedado en aislamiento por riesgo de Gripe A en los primeros filtros clínicos y realizar un seguimiento en el comportamiento de los grupos resultantes $+y-$ reclutando diferentes variables para determinar las diferencias entre ambos grupos y sobre todo las complicaciones posibles durante su ingreso.

\section{MATERIAL Y MÉTODO}

El Estudio descriptivo estadístico realizado es un estudio prospectivo, longitudinal y observacional, que abarca la totalidad de pacientes ingresados en la Unidad de Neumología del Hospital Virgen de Valme de Sevilla, durante el periodo mayo 2009 y abril 2010, un total de 79 casos, en medidas preventivas de aislamiento de contacto y gotas por posible gripe A. Esta Unidad de Neumología, por acuerdo con la Dirección del centro, fue designada la primera receptora de este tipo de grupos de riesgo.

En todos ellos desde su ingreso se les realiza un seguimiento en distintas variables para ver su comportamiento (Tabla 2), realizando el diagnóstico diferencial de PCR para H1N1 si no estuviera cursado previamente. Para el diagnóstico del virus de la gripe $\mathrm{A} / \mathrm{H} 1 \mathrm{~N} 1$ en humanos se deben obtener muestras de aspirado nasofaríngeo o, en su defecto, exudados nasal y faríngeo mediante escobillones, que se colocarán en un mismo tubo conteniendo medio de transporte especial para_virus (15). 


\section{TABLA 2}

\begin{tabular}{l}
\hline \multicolumn{1}{c}{ VARIABLES DEL ESTUDIO } \\
\hline NUMERO HISTORIA \\
DIAGNOSTICO DE INGRESO \\
TIEMPO ESTANCIA \\
COMPLICACIONES \\
PATOLOGIAS CRONICAS \\
EDAD \\
SEXO \\
GRIPE A + O - \\
DIAGNOSTICOS ENFERMEROS \\
\hline
\end{tabular}

Los resultados en un principio se obtenían en 48-72 $\mathrm{h}$ pues se enviaban al Centro de referencia de Andalucía ( $\mathrm{H}$. Virgen de las Nieves, Granada), aunque más tarde se obtenían desde el Servicio de Microbiología del H. Virgen de Valme en contacto con el servicio de Medicina Preventiva del mismo Hospital, y éstos se conseguían en 24-48 h . Durante ese periodo de espera al total de la población se les mantenían las medidas de aislamiento, preventivamente se trataba como grupo + con las medidas aconsejadas en Tabla 1. Una vez notificados los resultados se procedía a levantar el aislamiento, con la autorización de Medicina Preventiva, en los negativos y se continuaba con él en los positivos, pero manteníamos el seguimiento de las mismas variables en ambas poblaciones, para poder comparar ambos grupos.

Dentro de la variable patologías asociadas se estableció previamente la inclusión de si los pacientes eran fumadores o exfumadores importantes (más de $10 \mathrm{cg} . /$ día) y si existía embarazo, por ser datos relevantes y que en algunos estudios se reflejaban como grupos de riesgo.

Para mantener las condiciones óptimas de prevención en la Unidad de trabajo desde el Servicio de Medicina Preventiva del Hospital se procedió a la vacunación de los profesionales sanitarios de forma voluntaria, que mantuvieran contacto con los pacientes en aislamiento. Sin tener datos exactos, sí podemos decir que más de las 3/4 partes de la Unidad fue vacunada y que NO hubo casos positivos de Gripe A H1N1 confirmados entre ellos.

\section{RESULTADOS}

La población estudiada se dividió en $67 \%$ Gripe A + y 33\% Gripe A - 


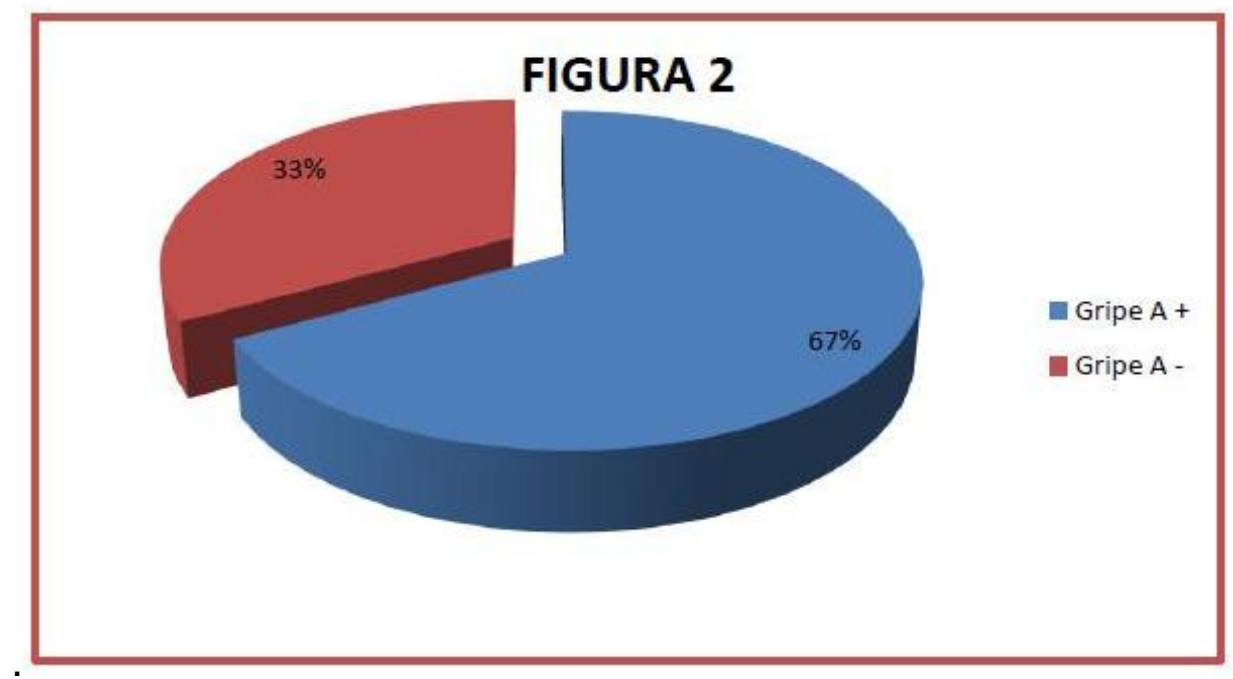

De los 79 casos del total de la población estudiada el $86 \%$ se ingresa por diagnóstico de Neumonía , el 14\% restante cumplían criterios establecidos de Hipoxemia con embarazo y/o Enfermedad Obstructiva Crónica.

En la población total el porcentaje de varones es mayor, mientras si desglosamos la población el porcentaje se invierte en los casos positivos ( $45 \%$ hombres $-55 \%$ mujeres), y en la población de negativos 7 de cada 10 casos son varones.

Si hablamos de la variable edad, la media en los pacientes Gripe A positivos es de 42 años y se sube hasta los 50 años en los grupos de negativos.

Cuando nos centramos en el tiempo de estancia medio de las dos poblaciones obtenemos casi un día más de ella en los pacientes negativos para H1N1. Positivos 5,7 días y negativos 6,6 días.

Los diagnósticos enfermeros más relevantes registrados fueron

\begin{tabular}{|l|l|l|}
\hline Población gripe A H1N1 & Positivos & \multicolumn{1}{|c|}{ Negativos } \\
\hline DX ENFERMERO ANSIEDAD & $68 \%$ & $56 \%$ \\
\hline DX ENFERMERO MANEJO INEFECTIVO & $17 \%$ & $12 \%$ \\
\hline DX ENFERMERO DESEQUILIBRIO & $7,5 \%$ & $0 \%$ \\
NUTRICIONAL POR EXCESO & & \\
\hline
\end{tabular}

Los fumadores se comportan en ambas poblaciones de forma diferente, mientras en los casos positivos tan solo el $45 \%$ son fumadores, en el grupo de negativos el porcentaje aumenta hasta el $61 \%$

Las complicaciones durante la estancia hospitalaria se produjeron en 2,3 de cada 10 casos en los pacientes Gripe A + y en 1,7 de cada 10 de los casos de Gripe A -. El 38,4\% de las complicaciones producidas entre los pacientes positivos fue ingreso en cuidados intensivos, mientras NO hubo ese tipo de complicación en los casos negativos.

\section{DISCUSIÓN}

A tenor de los datos los criterios de aislamientos parecen ser válidos por el porcentaje elevado de Gripe A positiva en ellos, casi 7 de cada 10 casos. Dentro de los criterios de 
ingresos hospitalarios como era de esperar en las patologías respiratorias altas destacan las neumonías.

Aunque el embarazo aparecía como factor de riesgo para la Gripe A en toda la bibliografía, comentar que tan solo fue hospitalizada en nuestra población de estudio 4 casos que suponen un 5,05 \%, aunque si denotar que 2 de estos casos, el $50 \%$, sufrieron complicaciones importantes (ingreso en U.C.I. por hipoxemia severa en un caso y aborto en el otro).

La población de pacientes Gripe A positiva es de media más joven y el sexo femenino es más predominante.

Según los datos obtenidos parece ser que los pacientes negativos para H1N1 requieren de mayor estancia hospitalaria aunque sufren menor número de complicaciones importantes que además en su mayoría suelen ser colocación de tubo pleural para evacuación de derrame paraneumómico, mientras el grupo de positivos las complicaciones están más relacionadas con Insuficiencia respiratoria grave que requieren control y ventilación mecánica No invasiva en Cuidados Intensivos.

Los pacientes del grupo de negativos son en porcentaje más fumadores que los positivos , pero dentro de estos últimos, casi 8 de cada 10 casos de complicaciones importantes se han dado en pacientes fumadores, es decir, los pacientes Gripe A + y fumadores tienen casi 4 veces más probabilidad de complicaciones que los NO fumadores.

La ansiedad relacionada con la alarma social por Gripe A se ve reflejada en el Estudio porque su índice aumenta en la población de positivos, y el hecho estresante de la hospitalización influye igualmente en ambos grupos y además el equipo de profesionales por los que han sido atendidos es el mismo por lo que la calidad de la atención sanitaria No debe de estar modificada.

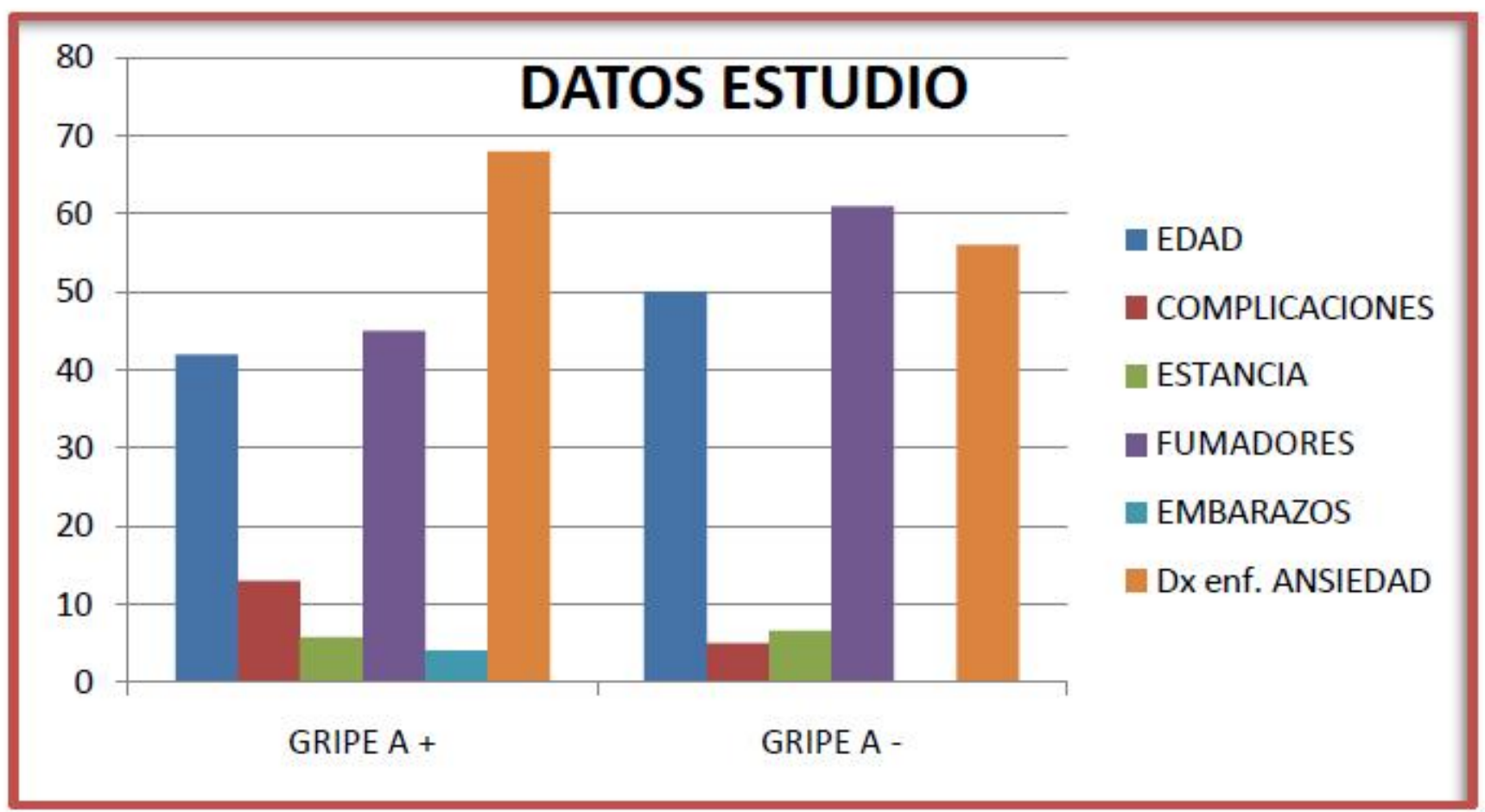




\section{CONCLUSIONES}

Las complicaciones desarrolladas por los pacientes Gripe A positivos durante su ingreso hospitalario tienen aproximadamente la misma incidencia pero mayor gravedad que las producidas en los pacientes Gripe A negativos durante los aislamientos hospitalarios recomendados por las autoridades sanitarias. Además las situaciones de embarazo y fumar aumentan la incidencia y complejidad de estas complicaciones .

\section{AGRADECIMIENTOS}

Para concluir desearía dar mi más sincero agradecimiento a todo el personal de enfermería, tanto auxiliares como diplomados de la Unidad, por haber realizado eficazmente su trabajo colaborando y facilitando así la recopilación de la base de datos de nuestro Estudio .

Muchas Gracias.

\section{BIBLIOGRAFÍA}

1 Base de datos de la OMS. 2009 Organización Mundial de la Salud. El nivel de alerta de pandemia de gripe se eleva de la fase 5 a la fase 6.Disponible en: http://www.who.int/mediacentre/news/statements/html.

2 Influenza A (h1n1). Temor a una pandemia. Jennifer Gotera y Nereida Valero Invest Clin 50(3): $279-281,2009$.

3 Ministerio de Sanidad . Informe seminal de Situación nacional sobre Pandemia Gripe A. Diciembre 2010

4 OMS. Actualizaciones de situación-pandémica (H1N1) 2009. 30 Abril 2010

5 Sistema de Vigilancia de la Gripe en España Red Nacional de Vigilancia Epidemiológica Área de Vigilancia de la Salud Pública. Centro Nacional de Epidemiología. Vigilancia de la gripe en España Semana 02/2010 (del 10 al 16 de enero de 2010)

6 U.S. pork groups urge hog farmers to reduce flu risk. 26 Abril 2009.

7 Soft evidence and hard sell. New York Times. 5 Septiembre 1976.

8 Deadly new flu virus in US and Mexico may go pandemic». New Scientist. 24-04-2009

9 World Health Organization: Swine flu could spread globally. CNN.com.

10 Guía para la gripe A para las familias . Ministerio de Sanidad. Grupo Técnico de Coordinación del Plan de Preparación y Respuesta frente a la Pandemia de Gripe. Septiembre 2009

11 Recomendaciones de Prevención y Manejo de la Gripe A/H1N1 para pacientes con Enfermedades de base Inmunológica . Comunidad de Madrid 2009

12 Protocolo de actuación ante casos de gripe A (h1n1) 2009 y recomendaciones generales en centros residenciales. Consejería de Salud Junta Castilla y León. Octubre 2009

13 Guía de prevención y protección frente a la gripe A de los profesionales de los centros asistenciales del SAS. Sistema de gestión de prevención de riesgos laborales Servicio Andaluz de Salud. Agosto 2009

14 Versión 10 . Adaptación a la situación epidemiológica y clínica actual .

11 de septiembre de 2009 . Plan Andaluz de Alerta Gripe A H1N1

15 Versión 8. Adaptación a la situación epidemiológica y clínica actual .

11 de septiembre de 2009 . Plan Andaluz de Alerta Gripe A H1N1 
